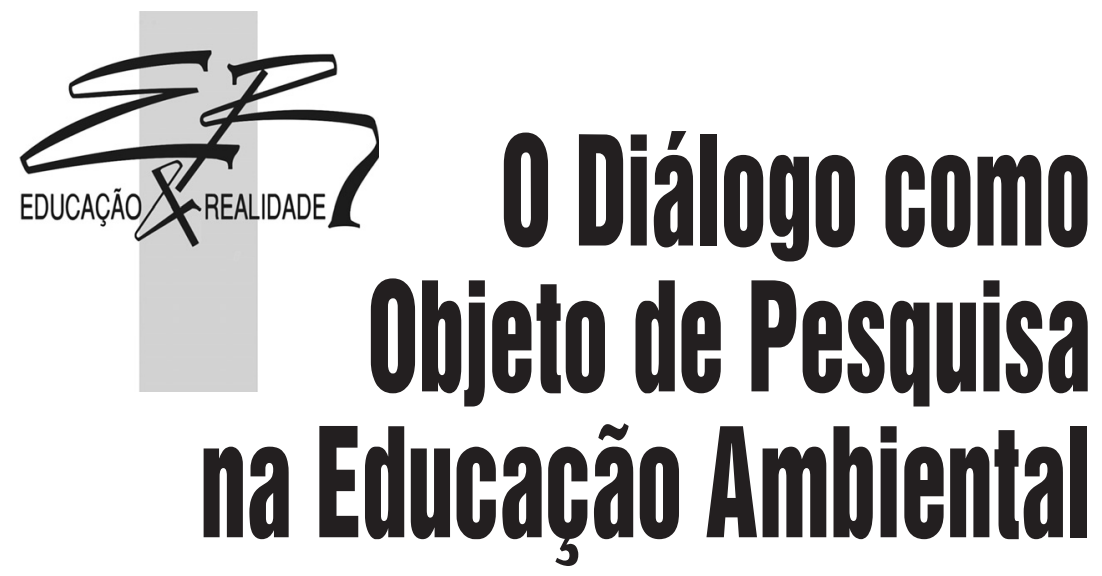

\author{
Andréa Quirino de Luca \\ Daniel Fonseca de Andrade \\ Marcos Sorrentino
}

RESUMO - O Diálogo como Objeto de Pesquisa na Educação Ambiental. Este artigo aborda o diálogo como objeto de pesquisa na Educação Ambiental, a fim de colaborar com a fundamentação de práticas e pesquisas na área. Observa a necessidade da criação de indicadores de diálogo e de maior aprofundamento empírico com aqueles já sugeridos. Também, o artigo promove uma articulação do conceito de diálogo com o de comunidades interpretativas e de aprendizagem, espaços para se praticar e vivenciar a Educação Ambiental (EA), práticas essas trazidas por algumas Políticas Públicas de EA brasileiras. Finalmente, argumenta que as metodologias participativas, sobretudo as de cunho intervencional, são adequadas para colaborar com um aprofundamento teórico-prático da teoria do diálogo.

Palavras-chave: Educação Ambiental. Diálogo. Conflito. Comunidades Interpretativas e de Aprendizagem.

ABSTRACT - Dialogue as a Research Object in Environmental Education. This article approaches the concept of dialogue as a research object in environmental education, to collaborate with other research and also practices in the field. The article points out the necessity to create dialogue indicators as well as of a deeper enquiry into existing ones. Also, the article articulates the concept of dialogue with the concept of interpretive and learning communities, which are spaces to practice and experience environmental education processes, as in some Brazilian EE public policies. In the end, it argues that participatory methodologies, mainly interventional ones, are appropriate to promote deeper inquiries into theoretical and practical aspects of dialogue.

Keywords: Environmental Education. Dialogue. Conflicts. Interpretatative and Learning Communities.

Educ. Real., Porto Alegre, v. 37, n. 2, p. 589-606, maio/ago. 2012.

Disponivel em: <http://www.ufrgs.br/edu_realidade> 


\section{Diálogo e Educação Ambiental}

Esse artigo trata da teoria do diálogo, de sua conexão com a Educação Ambiental (EA) e com a política pública de EA do Brasil. Pretende contribuir com pesquisas e práticas que abordem processos coletivos e dialógicos e com o enfrentamento das dificuldades que se apresentam ao longo desse caminho. Consideramos que esse é um campo com grande potencial a ser desenvolvido e aqui procuramos contribuir com essa questão, promovendo uma articulação entre teorias e métodos de pesquisa, anunciando dificuldades e apontando pontos que ainda devem avançar, para que tenhamos um arcabouço mais consistente nos processos dialógicos de EA.

A educação que a educação ambiental pretende, realiza-se na relação com o Outro, em como nos relacionamos com os outros humanos e com as demais formas de vida que nosso Planeta sustenta. É valorizando as relações e a forma como percebemos o Outro que a educação ambiental traz uma perspectiva de qualidade, de cuidado, de responsabilidade partilhada. E, como diz Paulo Freire (2000), ensinar exige disponibilidade para o diálogo. É quando ouço o que o Outro fala, às ideias do Outro, que posso organizar minhas ideias, saber como me colocar melhor, reconhecer as diferenças. No diálogo não há como se fechar ao mundo. Ao contrário, construímos saberes e nos reconhecemos como seres inacabados.

Seres inacabados no sentido mais orgânico da palavra, estamos sempre em construção, em processo, em movimento. Nas interações, com e no mundo, encontrando significados e novos significantes. Rompendo com a educação bancária tão bem explicitada por Paulo Freire (1987), a educação libertária que alimenta a educação ambiental traz como primeiro princípio em seu documento de referência, no Tratado de Educação Ambiental para Sociedades Sustentáveis e Responsabilidade Global, o seguinte termo: "A educação é um direito de todos, somos todos aprendizes e educadores" (Fórum Internacional de Organizações Não Governamentais e Movimentos Sociais, 1992; ou ainda no Anexo I do ProNEA - Brasil, 2005, p. 58).

Quando estamos conscientes de nosso inacabamento, percebemos com maior facilidade que há espaços para mudança e para aceitar o diferente. E a perspectiva do conviver com diferentes formas de ver o mundo, na diversidade das identidades, é também a perspectiva de trabalhar coletivamente. A educação ambiental nos oferece esse desafio: agir coletivamente, justamente o oposto do ser individual, tão arraigado nas práticas diárias de nossa sociedade.

No processo educativo de construção de uma nova identidade planetária, o diálogo tem importância primordial, enquanto meio para se formar uma amálgama entre as diversidades, entre os modos de viver, pensar, sentir e agir, tanto individual quanto coletivamente. É possível diminuir barreiras espaciais e cognitivas e conciliar as contradições inerentes à vida, sem descaracterizar ou anular a essência e as especificidades de cada pessoa ou grupo, promovendo e ampliando a comunicação e a interação entre os diversos. 
O diálogo é um exercício profundo de desvelamento que não tem limite final ou ponto de chegada, pois a vida está sempre em transformação. Desvendar-se e desvelar o Outro, num eterno entrelaçar de significados. Dialogando expomos nossa essência e ganhamos mais consciência de nós mesmos, de nossas fragilidades e fortalezas, virtudes e limitações, o que queremos e com o que não concordamos, encontrando nosso lugar na sociedade, que nada mais é do que a expressão da nossa identidade. O diálogo pode ser uma porta de entrada para a formação das conexões necessárias à construção não somente de uma identidade, mas de uma consciência e responsabilidade planetárias, que não constituem um produto pronto e acabado. Elas são sempre o resultado de um movimento constante de avaliação e reavaliação da nossa postura perante o mundo.

Estimular o exercício do diálogo é um desafio e uma necessidade para a educação ambiental que queremos realizar: aquela que fortalece e confere autonomia e confiança aos indivíduos, que promove a coexistência equilibrada entre as realidades e contextos pessoais e coletivos, entre o moderno e as tradições, entre a tecnologia e os saberes tradicionais e populares. O diálogo é uma via de acesso para a democratização das identidades e saberes diversos.

Ainda de acordo com Paulo Freire (1987), reconhecemos que o diálogo não existe sem a reflexão, mas traz em sua essência uma interação íntima e indissociável desta com a ação, sem exclusivizar nem a ação (evitando um tipo de ativismo que nega a reflexão), nem somente a reflexão (evitando a palavra oca, o blábláblá alienado/alienante). O diálogo, com estes elementos constitutivos é a Práxis, que pretende transformar, problematizar e pronunciar o mundo, para além da relação Eu-Tu, no encontro de mulheres e homens que se comprometem com esta pronúncia de mundo e, assim, ganham significação enquanto humanos: “[...] o diálogo é uma exigência existencial” (Freire, 1987, p. 79).

A sustentabilidade de processos educadores ambientais exige uma atitude sensível do educador-aprendiz perante o Outro, reconhecendo na alteridade sua via de ação, pois cada pessoa/grupo/comunidade num certo tempo/momento/ situação é único na sua interpretação. O certo, o bom, o melhor nunca está pronto e passível de ser entregue por um educador ambiental, e este deve romper de forma radical com a cultura ocidental do desejo de colonizar o outro.

Educadores ambientais, inspirados na educação dialógica da pedagogia libertária de Paulo Freire, buscam o desembrutecimento que processos pedagógicos coletivos podem estimular em seus participantes, tornando estes espaços de interação uma fonte de alimento intelectual, afetivo e racional, como forma de fortalecimento dos indivíduos, permitindo-nos enfrentar questões cotidianas comumente marcadas por injustiças socioambientais de forma mais equilibrada.

A educação ambiental dialógica traz humildade na escuta da pronúncia de mundo do Outro. Ela é autoconhecimento, pois traz a ação de reconhecimento de meus outros "eu", de minha própria ignorância que procuro não mais alienar. Traz também a fé nas mulheres e homens e no seu poder de fazer e refazer. Não uma fé ingênua, mas dialógica e crítica, que sabe que o homem é um ser 
histórico e tem o poder de transformar ao agir coletivamente na luta pela sua libertação, pautado na esperança de seu fazer, que vem de nossa essência de imperfeição e que sempre nos leva a uma eterna busca (Freire, 1987). Entretanto, reconhecer as potencialidades do diálogo demanda também o vislumbre de suas limitações e dos desafios inseridos nos processos que se pretendem dialógicos. Algumas dessas questões serão apresentadas no item a seguir.

\section{O Que É Diálogo?}

A necessidade de diálogo é justificada atualmente pela complexidade e interdependência dos problemas institucionais e globais, que não permitem mais o pensamento individual. Da mesma forma, o simples fato de pessoas conversarem não significa a ocorrência do diálogo rumo à resolução desses problemas, já que as falhas de comunicação e desentendimentos culturais que ocorrem não permitem a abordagem das questões de forma comum, tornando impossível uma lida construtiva dos problemas. Por isso, há uma motivação para o desenvolvimento da capacidade de se pensar junto, desenvolver pensamento colaborativo e ação coordenada (Isaacs, 1993).

Segundo Bohm (2005), a palavra diálogo provém do grego dialogos, significando em última instância, uma corrente (ou fluxo) de significados (dia: através de; logos: o significado da palavra) entre nós e através de nós, contrariando o senso comum, que atribui à palavra a noção de dois (di). Assim, o diálogo pode acontecer com qualquer número de pessoas, inclusive individualmente, dado que as condições para sua ocorrência estejam presentes. O fluir de significados propicia, então, a construção de algo novo, não existente anteriormente, um significado compartilhado coerente, que, de acordo com o autor, é a cultura, que é o que mantém pessoas e sociedades unidas. Quando os significados compartilhados não são coerentes, há então problemas na organização social, porque se perde a capacidade de comunicação com profundidade.

Em geral, diálogo é confundido com debate, consenso, discussão ou negociação. Entretanto, uma análise mais aprofundada dos quatro demonstra rapidamente a diferença. Isaacs (1993) aborda o debate elucidando sua raiz, bater, processo em que necessariamente um lado ganha e o outro perde ambos mantém seus pressupostos e não há reflexão mais aprofundada sobre eles. Aborda também o consenso, cuja raiz significa se sentir junto, que tem como objetivo encontrar uma visão que reflita o que a maioria possa tolerar. Da mesma forma que o debate, não altera os padrões fundamentais que levaram as pessoas a discordarem no primeiro momento, ou seja, também não tem a ambição de explorar os padrões de significado presentes. Já discussão provém da mesma raiz de concussão e percussão, que significa partir as coisas, e é um processo em que os diferentes pontos de vista serão analisados em separado com objetivo, também, de ganhar o jogo. Finalmente, na negociação, o que ocorre é um processo de ajuste de todas as partes envolvidas de forma a satisfazer a 
todos. Apesar de importante, também não toca nos aspectos fundamentais para a ocorrência do diálogo (Bohm, 2005).

Os processos acima abordados possuem todos, um aspecto em comum. Em nenhum deles toca-se no que Bohm (2005) chama de pressuposições de raiz: pressuposições profundas formadas ao longo da experiência de vida das pessoas com as quais constroem senso da vida e da realidade. Essas pressuposições de raiz são, em geral, defendidas com vigor quando desafiadas, pois as pessoas identificam-se a si mesmas com suas pressuposições e qualquer oposição a elas soará como uma ofensa pessoal. A resposta esperada a isso é, então, uma forte reação emocional, que impede a comunicação posterior, pois quando defendemos uma opinião não conseguimos pensar juntos. Por outro lado, quando alguém não escuta nossas pressuposições, então isso nos parece uma violência. E se dois lados opostos possuem certezas intocáveis, como compartilhar?

E esse é um dos obstáculos ao diálogo discutidos por Schein (1993). Em seu texto, o autor coloca que nós somos culturalmente treinados para esconder informações que de alguma forma ameaçariam a ordem social, ou seja, preferimos ser educados a sinceros, o que cria o que Chrys Argyris, citado pelo autor, chama de rotina defensiva. Se por um lado isso permite o convívio social e a não externalização de conflitos, por outro impede o diálogo mais aprofundado e a compreensão das pressuposições de raiz que embasam as opiniões. Sacrifica-se a comunicação e o entendimento em nome de uma posição social (Schein, 1993).

Outro obstáculo ao diálogo são os papéis que as pessoas assumem para si a partir de suas experiências de vida. Algumas se colocarão como dominantes outras nem tanto e esses papéis emergirão no processo de construção do diálogo (Bohm, 2005). A fragmentação do pensamento e a defesa das partes é também uma dificuldade reconhecida para o processo (Isaacs, 1993). Por isso, convicção e persuasão não seriam indicadas para estarem presentes em um diálogo. Ao se tentar vencer por meio de palavras - convencendo com uma conversa dura ou persuadindo com uma conversa suave - não se constroem pensamentos coerentes. Da mesma forma, não se espera a participação de princípios de hierarquia e autoridade num diálogo, o que traria bloqueios (Bohm, 2005).

Diferentemente dos processos elucidados acima, no diálogo ninguém está querendo ganhar ou, quando alguém ganha, todos ganham (Bohm, 2005). Segundo Buber (1979), o diálogo está no reconhecimento do ser no outro, escondido em seus papéis sociais, que por sua vez, o objetificam e conferem ao ser uma utilidade, uma função. Buber (1979) diferencia então a relação $E u$-Tu, de encontro entre a essência dos seres, da relação Eu-Isso, fundamentalmente utilitária. A primeira propicia uma relação, que pode se dar em três esferas, a vida com a natureza, a vida com os homens e, finalmente, a vida com os seres espirituais. A segunda, por sua vez, propicia uma experiência, no sentido em que coisifica o outro, tornando-o um objeto, e permite sua exploração, manipulação e controle. A primeira ocorre na presença, no encontro e na relação. 
Presença, no entanto, que aguarda e permanece não que é passageira. Já a segunda é vivida no passado, pois o objeto é estagnado, interrompido, desvinculado, ausente de presença.

Para Bohm (2005), o diálogo está passivo de ocorrer quando as partes forem capazes de reconhecer suas pressuposições e as dos outros e, em um processo, deixá-las em suspenso, ou seja, sem trabalhá-las ou suprimi-las, sem acreditálas ou desacreditá-las, sem julgá-las boas ou más, mas simplesmente ver o que elas significam. Assim, dialogar significa encontrar tempo para perceber o que se passa nas nossas mentes e dos outros, sem fazer julgamentos ou chegar a conclusões. Schein (1993) é ainda mais preciso em sua colocação, deixando claro que na maioria dos casos em que esteve envolvido em processos de diálogo, utilizou a maior parte do tempo tentando compreender o que as suas próprias pressuposições eram, mais do que prestando atenção nas dos outros.

Ao se observar o que todas as opiniões significam, se estará formando um conteúdo compartilhado comum e menor importância se dará às opiniões individuais, pois será possível se verificar que tais opiniões são apenas derivadas de pressupostos. O processo de revelar pressuposições permite também que as pessoas livrem-se delas ou ao menos sejam capazes de analisá-las criticamente, para ir além delas. Precisaríamos buscar compartilhar um significado comum, para então participarmos juntos do mesmo pensamento. A direção a ser tomada é para algo novo e criativo (Bohm, 2005).

Por fim, o diálogo busca o aprendizado "[...] do contexto e da natureza dos processos pelos quais as pessoas formam seus paradigmas" (Isaacs, 1993, p. 38), é a forma coletiva de aliviar julgamentos e avaliar pressuposições (Bohm, 2005), fazendo com que as pessoas sejam capazes de perceberem-se como participantes de um conjunto de significados compartilhados (Isaacs, 1999).

Para que o diálogo seja incentivado é necessário, então, a criação de um espaço ou ambiente propício para isso, em que são ouvidas todas as opiniões sem nada ser feito, sem agenda ou objetivos especiais ou necessidade de concordância. O ouvir compartilhado fará com que as pessoas fiquem juntas, pois formará uma sensação de confiança entre elas (Bohm, 2005). É necessária, no entanto, uma postura colaborativa entre os participantes para que ocorra o diálogo, decorrente de uma escolha individual em colaborar, com a finalidade de se conseguir o máximo de uma conversa (Schein, 1993).

Mesmo sabendo das dificuldades que se pode enfrentar, e destacando a importância para que não cedamos às frustrações, Bohm (2005) diz que se pudessem ser deixado em suspenso todos os impulsos e as pressuposições, e se fosse possível olhar com uma posição observadora para elas, todos os envolvidos no diálogo atingiriam o mesmo estado de consciência, estabelecendo-se a consciência comum. Se o processo possibilitar que as pessoas se tornem conscientes dos mecanismos pelos quais formam suas pressuposições e suas crenças e sejam, de alguma forma, recompensadas por isso, então estará nascente uma força e capacidade para trabalhar e criar coisas em conjunto. O espaço de diálogo é, portanto, um espaço de investigação com a finalidade de transformar a qua- 
lidade da conversa e, principalmente, o pensamento subjacente a ela (Isaacs, 1993). Ao propiciar as condições em que as influências sutis e tácitas sobre o pensamento sejam alteradas, o diálogo possibilita uma transformação da natureza da consciência, permitindo a emergência de novos tipos de inteligências individuais e coletivas, em substituição dos padrões mentais existentes quando as questões a serem lidadas foram criadas. Apesar da urgência e importância de diálogo para o mundo atual e da ancestralidade da prática, cientificamente a teoria do diálogo permanece ainda em um estado embrionário.

\section{O Diálogo a partir de Comunidades Interpretativas e de Aprendizagem}

O Órgão Gestor da Política Nacional de Educação Ambiental, criado a partir da Lei Federal 9.795 de 1999 (Brasil, 1999) e regulamentado pelo decreto 4.281 de 2002 (Brasil, 2002), criou o ProFEA - Programa de Formação de Educadores Ambientais: por um Brasil educado e educando ambientalmente para a sustentabilidade - (Brasil, 2006). Esse programa propõe uma metodologia para se trabalhar e praticar EA, as chamadas comunidades interpretativas e de aprendizagem, que seriam espaços dialógicos que fortalecem a participação e a solidariedade entre os sujeitos envolvidos.

Tal metodologia não tem um desenho fixo, devendo ser moldado pelos próprios participantes, que são sujeitos que trazem suas histórias, seu tempo e seu lugar, para construir saberes de forma compartilhada. Sabendo que o entendimento de mundo que temos, como seres inacabados, sempre pode ser complementado com outros saberes, estes espaços trazem a possibilidade de trocas de saberes e experiências, o que pode também apoiar o aumento da habilidade argumentativa de seus participantes e nos permitir vivenciar a experiência da coletividade: saber ouvir, saber ser solidário, saber respeitar-nos e respeitar o outro.

As comunidades interpretativas e de aprendizagem permitem abertura à horizontalidade de ações e devem se fechar à hierarquia de poderes e saberes, favorecendo, assim, o diálogo como proposto neste artigo. Esta metodologia de trabalho está baseada nos conceitos de comunidades interpretativas do sociólogo português Boaventura de Souza Santos, e nos círculos de cultura do educador brasileiro Paulo Freire.

Os círculos de cultura seriam grupos de diálogo onde todos os participantes poderiam educar e educarem-se, baseado na prática dialógica que busca a ação e reflexão, enraizando o homem no contexto histórico e, portanto, político e ideológico (Freire, 2009).

No lugar de um professor, Freire (2009) sugere a figura de um coordenador, que não impõe, mas coordena. No lugar de uma educação autoritária, uma pedagogia libertadora: grupos de trabalho e de debate, de crítica, de participação, exercício de democracia. Mulheres e homens do povo que, a partir de situações 
desafiadoras, aqui tidas como questões socioambientais produzidas historicamente, passam pela ação dialogal e ativa, num viés que busca a profundidade na interpretação dos problemas.

Esse método de ensino de Freire (2009), que se assenta na prática do diálogo e não da polêmica, passa também pela conquista da segurança na argumentação. O caminho do diálogo é aqui também o processo de transformar dimensões de consciência ingênua, que aceita condições mágicas, numa consciência crítica, integrada com a realidade, que desemboca em ação e nova reflexão, e que, assim, colabora com a organização reflexiva do pensamento.

Para Freire (2009, p. 78): "A dialogação implica na responsabilidade social e política do homem. [...] Não há autogoverno sem dialogação". E cita, ainda (2009, p. 150): "A democratização da cultura, disse certa vez um desses anônimos mestres analfabetos, tem de partir do que somos e do que fazemos como povo. Não do que pensem e queiram alguns para nós".

Vale ressaltar que esta noção de Política Pública construída através de diálogo com o povo está em consonância com as políticas do ProNEA (Brasil, 2005), e ProFEA (Brasil, 2006), e embora reconhecendo a importância do conteúdo que tais documentos delineiam, muito ainda deve avançar tanto em teoria como na prática. A tentativa de fundamentar os conceitos de diálogo e de comunidades interpretativas e de aprendizagem deste artigo procura apoiar algumas questões neste sentido.

Muitas das ideias de Freire e de seu círculo de cultura caminham na mesma direção das comunidades interpretativas de Santos (2007), que também seriam espaços de aumentar a capacidade argumentativa e comunicativa dos participantes na direção de conhecimentos emancipatórios, baseados em ações que se pautam na solidariedade e na participação.

Outros aspectos igualmente dialogam com as ideias colocadas por Freire: Santos (2007) traz a noção de que nossos conhecimentos sobre nós mesmos e sobre o mundo são incompletos por si, e podemos ter uma compreensão mais ampla na horizontalidade, nas interpretações a partir do coletivo, do Outro, da comunidade interpretativa em si, que contribuem para a repolitização da vida comunitária.

Fica claro que a busca na comunidade interpretativa não é do consenso. Confrontos de interpretações geram desestabilização de nossas certezas e dificilmente podemos alcançar um acordo coletivo sobre o que o mundo é ou deveria ser (Avanzi; Malagodi, 2005). Porém, essa desestabilização das certezas é o que pode nos permitir construir algo novo, o que pode nos dar uma compreensão mais profunda das questões socioambientais de nosso tempo e lugar, fazer-nos perceber nossos traços de colonialismos, heranças do pensamento ocidental. Pode nos permitir deslocar nossas ações no sentido de conceber a solidariedade como forma de saber, portanto, como um valor.

Para Santos (2007), as comunidades interpretativas seriam espaços de cidadania que poderiam possibilitar condições de experimentação de sociabilidades alternativas. Essas deveriam procurar estarem centradas em torno do Estado, 
numa tentativa de transformá-lo e até reinventá-lo radicalmente, na direção de, ao invés de condicionar práticas sociais, fator principal por trás das formas hegemônicas de sociabilidades, este possa criar condições necessárias para que as sociabilidades alternativas venham a ser credivelmente experimentadas.

Portanto, as comunidades interpretativas e de aprendizagem são consideradas comunidades também políticas, no sentido que nos fala o Tratado de EA para Sociedades Sustentáveis e Responsabilidade Global (Brasil, 2005, p. 58) "[...] a educação ambiental não é neutra, mas ideológica. É um ato político". Uma "comunidade interpretativa e de aprendizagem" é "[...] lugar de pesquisa, avaliação, reflexão, decisões, prática, ações, afetividade, cultivos, cultura" (Brasil, 2006, p. 43).

Devemos ter nestes espaços, ainda, a possibilidade de diálogo sobre os conflitos que, tendo um direcionamento para a ressignificação, podem se constituir não mais como algo negativo, mas como "alavanca para a mudança" (Malagodi, 2007, p. 79). Diálogo de saberes também traz tensões de saberes, mas somente a partir de um exercício de diálogo que nos permita construir algo novo - na direção da possibilidade de mudança de padrões-, esse pode nos permitir consolidar processos educadores ambientais transformadores.

Os Instrumentos de Política Pública de EA instituídos pelo Órgão Gestor da Política Nacional de Educação Ambiental que propõem o trabalho através de comunidades interpretativas e de aprendizagem, são as Com-Vida e os Coletivos Educadores (Comissão de Meio Ambiente e Qualidade de Vida nas escolas, propostas pelo Ministério da Educação e Comunidades Interpretativas sobre Meio Ambiente e Qualidade de Vida, propostas pelo Ministério do Meio Ambiente).

Coletivos Educadores são grupos de educadores ambientais de várias instituições e movimentos sociais que desenvolvem processos formativos continuados e permanentes num determinado território. Grupo articulado de pessoas que aprendem participando e que, juntos, interpretam a realidade socioambiental de seus lugares, planejam intervenções educadoras, implementam e avaliam tais intervenções, vivendo, assim, a pedagogia da práxis (Brasil, 2006).

Um Coletivo Educador tem o papel de:

[...] promover reflexão crítica, aprofundamento conceitual, instrumentalização para a ação, pró-atividade de seus participantes e articulação institucional visando à continuidade e sinergia de processos de aprendizagem de modo a permear, de forma permanente, todo o tecido social do território estrategicamente estipulado (Brasil, 2006, p. 34).

As Com-Vidas/MEC também partem das reflexões e práticas propostas pela pedagogia libertadora dos círculos de cultura, e são grupos de estimulam processos de educação ambiental junto, sobretudo, ao ensino formal, estimulando a mobilização da comunidade escolar (Brasil, 2006).

Assim, configuram-se como políticas que apoiam movimentos de organização para o diálogo, ancorando a compreensão de que o Estado pode e deve 
exercer o papel de estimular a repolitização da vida comum do cidadão, que por sua vez pode vir a exercer uma cidadania mais participativa. E é o exercício do diálogo que, em espaços educadores, nos prepara para a alteridade e para uma compreensão mais aprofundada dos processos sócio-históricos construídos e suas consequências socioambientais.

\section{O Exercício para o Diálogo: o conflito e os pressupostos de raízes}

Partindo, então, dos conceitos de diálogo e de comunidades interpretativas e de aprendizagem postos neste artigo, trazemos aqui outros pontos de ancoragem conceituais a fim de fundamentar práticas críticas e reflexivas de EA.

Considerando, então, que a questão do diálogo é ainda muito incipiente nas bases aqui mencionadas, acredita-se necessário aprofundar outros conceitos vinculados a este, que interagem muito substancialmente com as práticas dialógicas da EA crítica.

Inicialmente trazemos a abordagem da transdiciplinaridade, que busca tratar de um tema comum através do estabelecimento da intercomunicação entre as disciplinas através de fóruns de discussões, diálogo entre saberes, de metodologias participativas, na direção de um diálogo criativo e cooperativo para enriquecimento mútuo, sem perder de vista a questão das incertezas (Oliveira, 2005).

Esta abordagem está sustentada pela complexidade, pelo entendimento de que existem diferentes níveis de reconhecimento de realidade e, finalmente, a lógica do terceiro incluído, sendo que são estes fatores que devem nortear a pesquisa e a prática transdisciplinar (Oliveira, 2005).

Devemos considerar que a criação de espaços para o diálogo de saberes inclui a dimensão do confronto de saberes, ainda que não explicitado (Oliveira, 2005). Esse conflito e essa disputa podem, porém, pautar-se no princípio da complementaridade de saberes e práticas, num constante exercício de ressignificação das questões em pauta (Floriani, 2007).

Temos, assim, a necessidade da ressignificação da questão dos conflitos que necessariamente estão presentes na convivência de coletivos educadores, e reconhecemos aqui a necessidade de manejar noções a esse respeito, a fim de dar suporte a essas práticas, visando a sustentabilidade desses processos.

Malagodi (2007, p. 79), citando Moscovici e Doise (1991), é quem contribui com essa ressignificação: "[...] o conflito é a alavanca da mudança”. Concordamos que a expressão espontânea deva ser estimulada e que o silêncio deva ser combatido, ou seja, os membros de um coletivo devem, numa relação horizontal e numa atitude dialógica, encorajar opiniões diferentes sobre um mesmo tema, numa atitude de respeito pela pluralidade do grupo.

A isso, somamos o conceito de inacabamento do ser trazido por Freire (2000, 2009) e a desestabilização das certezas de Santos (2007), com a noção de 
construção coletiva de algo novo trazido por Bohm (2005): assim se manifesta o verdadeiro exercício do diálogo aqui discutido.

A ordem e o consenso são valores trazidos pelo discurso da modernidade, mas quando nos conscientizamos de nossa finitude como seres inacabados, podemos nos colocar abertos a esse exercício. Voltamos às questões trazidas inicialmente neste artigo: saber ouvir, saber ser humilde, (re)conhecer o Outro pelo Outro. Também nos deparamos novamente com a necessidade de deixar nossos pressupostos de raiz suspensos, como nos diz Bohm (2005).

O conflito é inerente ao processo de aprendizagem, aqui considerado como processos de significação e resignificação, tomando como base que somos animais simbólicos em interação, pois nossa relação com o mundo é mediada pelo simbólico.

A implementação de processos coletivos que se transformem em efetivas 'comunidades interpretativas e de aprendizagem' depende, entretanto, do reconhecimento das limitações do diálogo e dos obstáculos que emergem. Como coloca Yanchelovich (2001), o diálogo como considerado aqui não surge em todas as ocasiões. O extremo é quando temos um conflito entre interesses que são, a princípio, irredutíveis, ou seja, os participantes não querem abrir mão de suas posições de maneira nenhuma. Tem-se aí uma polarização que impede o diálogo em absoluto. Outra possibilidade é quando o conflito emerge dentro de um processo coletivo e que pode levar a diferentes situações. Uma delas é o racha, a divisão do grupo (como ocorreu no Coletivo Educador Ambiental de Ribeirão Preto) ${ }^{1}$ ou simplesmente sua dissolução. A outra é o grupo resistir e sobreviver às crises, como ocorreu durante o processo de formação do Coletivo Educador Ambiental de Campinas (COEDUCA). Apesar do conflito ter permeado as relações e decisões no processo de formação, houve a construção de vínculos afetivos e de pertencimento e crescente qualidade de participação de seus integrantes, conforme relatado em Luca; Cardoso; Costa-Pinto (2009) e em Costa-Pinto; Luca; Castellano (2008).

Quando o conflito é encarado como um problema a ser resolvido, o esforço de um coletivo para garantir o consenso pode passar a ter sentido de força coercitiva, controle e vigilância (Malagodi, 2007). O agir democrático traz o conflito como constitutivo, pluralidade de histórias de pessoas, de suas formas de interagir com suas questões individuais e coletivas. Não se trata, portanto, da busca do consenso que anula, mas da percepção do conflito como meio e não como fim. Considera-se aqui que um conflito determinado possa ter vários desdobramentos, não apenas o do racha. É necessário, portanto, aprendizado sobre como lidar com situações desse tipo.

Cabe ressaltar que, entre todos os desafios que podemos encontrar, dois são especialmente comuns e merecem atenção do grupo que se pretende dialógico, já que são fortemente arraigados ao paradigma que vivenciamos: a falta de tempo dos participantes e a necessidade de nos apegarmos aos resultados e produtos (hábito relacionado ao utilitarismo) ao invés de ter atenção à aprendizagem do processo. 
Para enfrentar essas questões, os grupos devem entender o planejamento do projeto e os objetivos dos encontros (transparência no processo) e certo grau de flexibilidade é necessário. Exercícios de autoanálise e diálogos sobre a autogestão nos ajudam a desenvolver adequadas ferramentas para avançar nestas questões.

Experienciar novas sociabilidades, como nos fala Santos (2007), passa por enfrentarmos coletivamente os gargalos encontrados ao longo do caminho de exercício do diálogo. Nesse sentido, o diálogo não pode ser limitado a uma mera metodologia de resolução de conflitos, mas compreendido como um espaço que propicia a convivência segura na diversidade (Isaacs, s. d.). Desenraizarmos os saberes individualistas e competitivos tão cotidianamente experimentados nesse paradigma ocidental, ou ainda, lidarmos com as noções de hierarquias e relações de poderes da forma como funcionam em nossa sociedade não é tarefa fácil ou corriqueira. Assim, podemos ter a escolha de assumir nosso comprometimento com esse novo saber: contribuirmos com a criação de sentidos e saberes de coletividade.

\section{Pesquisando o Diálogo na Educação Ambiental}

Métodos qualitativos de pesquisa podem responder a questões particulares com um nível de realidade que não pode ser quantificado, pois trabalham com o universo de significados, motivos, aspirações, crenças, valores e atitudes, correspondendo a um espaço mais profundo das relações, dos processos e dos fenômenos que não podem ser reduzidos à operacionalização de variáveis (Minayo, 1998).

Dentre os métodos qualitativos, as pesquisas participativas são os mais adequados para que o diálogo seja tomado como objeto de pesquisa na Educação Ambiental. Tais métodos têm como princípios e ações a promoção de avaliação e reflexão sobre as próprias práticas, o compromisso com a causa popular, a formação de processos pedagógicos a partir das bases, a consideração dos aspectos de justiça social que permeiam os contextos, o desenvolvimento de projetos e programas de pesquisa com a base empírica de uma situação real e o desenvolvimento de instrumentos de trabalho com coletividades que, de fato, garantam a participação efetiva dos envolvidos. Esse método baseado na práxis que, através de um processo espiral de ação-reflexão-ação, promove ações mais qualificadas e contribui com a ampliação da consciência das bases sociais em relação à situação socioambiental em que estão inseridas, valorizando o conhecimento popular (Barbier, 1985; Thiollent, 1985; Brandão, 1986; 1999; 2005; Tozoni-reis, 2005; Viezzer, 2005).

A pesquisa-intervenção, que também se constitui como pesquisa participativa e tem como objetivo promover um processo investigativo na vida da comunidade na sua diversidade qualitativa, aqui é tida como importante linha. Essa forma de pesquisa se afirma como um ato político, acentuando o vínculo 
entre as origens teórica e social dos conceitos, propondo uma intervenção de dimensão micropolítica no cotidiano social visando à transformação da realidade sociopolítica (Rocha; Aguiar, 2003).

Essa tendência de pesquisa se iniciou no Brasil na década de 70 do século $\mathrm{XX}$, questionando os pressupostos das pesquisas tradicionais relativos à relação entre o investigador e o investigado, entre sujeito e objeto, teoria $\mathrm{e}$ prática (Rocha, 2006), o fracionamento da vida social, a dicotomização entre ciência e política e, assim, a impossibilidade da inclusão de atores excluídos na delimitação dos seus próprios futuros (Rocha; Aguiar, 2003).

Os passos metodológicos e as técnicas utilizadas para o levantamento de dados de processos dialógicos aqui indicados são a observação participante e os grupos focais.

A observação participante requer do pesquisador uma atitude de simpatia, sensível à personalidade das pessoas (Barbier, 1985). Este método permite o contato direto do pesquisador com o fenômeno a ser observado, assim como obter informações sobre a realidade dos atores sociais inseridos em seu próprio contexto (Minayo, 1998).

Segundo Valles (1997), técnicas de observação participante são aquelas em que o investigador presencia diretamente o fenômeno que estuda não se atendo apenas às informações indiretas fornecidas por entrevistas ou documentos, na busca de realismo e construção de significado, contando com o ponto de vista dos sujeitos estudados. Ela diferencia-se da observação comum por ser orientada e focada no objetivo concreto da investigação, definido previamente, por ser planejada em fases, aspectos, lugares e pessoas, por ser controlada e relacionada com proposições e teorias sociais e por ser submetida a controles de veracidade, objetividade, confiabilidade e precisão (Olabuénaga; Ispizua, 1989, apud Valles, 1997).

Os dados das observações participantes devem ser coletados por meio de um caderno composto por notas de campo, que são "[...] o relato escrito daquilo que o investigador ouve, vê, experiencia e pensa no decurso da coleta e refletindo sobre os dados de um estudo qualitativo" (Bogdan; Biklen, 1994, p. 150). Aí se incluem "[...] a descrição de pessoas, objetos, lugares, acontecimentos, actividades e conversas. Em adição e como parte dessas notas, o investigador registrará ideias, estratégias, reflexões e palpites, com como os padrões que emergem" (Bogdan; Biklen, 1994, p. 152). De acordo com os autores, as notas de campo possuem um componente descritivo, em que a preocupação é "captar uma imagem por palavras do local, pessoas, acções e conversas observadas" (Bogdan; Biklen, 1994, p. 152) e um componente reflexivo, que apreende mais o "[...] ponto de vista do observador, suas ideias e preocupações" (Bogdan; Biklen, 1994, p. 152).

Os grupos focais podem ser compostos em diferentes momentos do processo do exercício do diálogo: por exemplo, um no início do processo de intervenção e um segundo ao final do processo de intervenção com o intuito estabelecer se a participação no processo dialógico colaborou para o enraizamento dos sujeitos participantes nos coletivos pesquisados. 
Segundo Neto, Moreira e Sucena (2002), o grupo focal é “[...] uma técnica de pesquisa na qual o pesquisador reúne, num mesmo local e durante certo período, uma determinada quantidade de pessoas que fazem parte do públicoalvo de suas investigações, tendo como objetivo coletar, a partir do diálogo e do debate com e entre eles, informações acerca de um tema específico" (p. 5). Ainda segundo os autores, a principal característica da técnica é o fato dela

[...] trabalhar com a reflexão expressa através da "fala" dos participantes, permitindo que eles apresentem, simultaneamente, seus conceitos, impressões e concepções sobre determinado tema. A "fala" que é trabalhada nos GF não é meramente descritiva ou expositiva; ela é uma "fala em debate", pois todos os pontos de vista expressos devem ser discutidos pelos participantes. Exatamente por isso, as questões aventadas pelo pesquisador devem ser capazes de instaurar e alimentar o debate entre os participantes, sem que isso equivalha à preocupação com a formação de consensos. Logicamente, algumas opiniões causam mais impacto e polêmica que outras, gerando reações que ora convergem ora divergem. O importante é que todos tenham possibilidades equânimes de apresentar suas concepções e que elas sejam discutidas e refinadas (Neto; Moreira; Sucena, 2002, p. 5-6).

O enraizamento dos atores participantes do processo de diálogo em coletivos pode ser avaliado de diversas formas, e aqui apontamos duas maneiras:

1. Durante os processos de intervenção, por meio de indícios que demonstrem o enraizamento, presença e frequência nos dias de atividades, a participação no grupo, questões feitas, envolvimento com as discussões, sugestões oferecidas e a responsabilização pelo desempenho de atividades/ tarefas elencadas pelo grupo.

2. Por meio dos depoimentos e impressões coletadas com os grupos focais, no início e ao final do processo, também na busca de indícios de tal enraizamento.

\section{Considerações Finais}

A relação entre diálogo e educação, conforme abordado acima, foi discutida amplamente por Paulo Freire (1987; 2000; 2009), entre outros, ao longo de sua história, como consequência do reconhecimento e forma de superação da incompletude individual e da construção de significados coletivos. Ao propiciar processos de desvelamento e, portanto, percepção mais nítida sobre os objetos observados, o diálogo incita também o desvendamento dos sujeitos, remetendo-os aos processos pregressos de pensamento que justificavam os conteúdos de seus pensamentos (Tassara; Ardans, 2005). Em outras palavras, o sujeito (individual e coletivo) se torna mais esclarecido e crítico sobre (suas) próprias lentes, com as quais olha e compreende o mundo, o que propicia um fortalecimento de suas identidades (Tassara; Ardans, 2005). 
A relação entre o diálogo e a educação ambiental é também muito nítida e se apresenta como a base de diversos documentos internacionais, como o Tratado de Educação Ambiental para Sociedades Sustentáveis e Responsabilidade Global (Fórum Internacional de Organizações Não Governamentais e Movimentos Sociais, 1992), como nacionais - o Programa Nacional de Educação Ambiental (Brasil, 2005) e Programa Nacional de Formação de Educadoras(es) ambientais: por um Brasil educado e educando ambientalmente para a sustentabilidade (Brasil, 2006), além de outros. A EA propõe, por meio da formação de comunidades interpretativas e de aprendizagem, a construção de espaços em que conversas acerca de aspectos socioambientais possam ser mediadoras de uma real democratização política (Santos, 2008).

A promoção de espaços de diálogo demanda, no entanto, o desvelamento do próprio conceito, a fim de que a sua melhor compreensão oriente as ações subsequentes. Parte da proposta deste artigo se deu nesse sentido, de qualificar o conceito como forma de norteamento de práticas.

O que se encontrou, no entanto, foi que a inserção do diálogo como objeto de pesquisa é um fato relativamente recente e remonta, de forma mais intensiva, ao início dos anos de 1980 (Yanchelovich, 2001). Isso significa que uma teoria operacional está ainda em processo inicial de construção (Isaacs, 1993). Foi dentro deste contexto que o presente artigo foi idealizado. Ou seja, diante da importância de processos dialógicos na educação e também no campo mais específico da educação ambiental, de se sugerir, a partir da teoria do diálogo proposta, metodologias de pesquisa que sejam capazes não só de reconhecer, mas também de se produzirem as condições para que o diálogo ocorra dentro de grupos. E aqui sugerimos dois métodos de pesquisa-intervenção inseridos no rol das pesquisas participativas que podem colaborar para isso, a observação participante e a formação de grupos focais.

Um dos aspectos fundamentais, no entanto, para um melhor aprofundamento da teoria operacional do diálogo é a criação de indicadores que demonstrem a sua emergência. Bohm (2005) aborda a importância dos eventos de suspensão de pressupostos. Yanchelovich (2001) fala da ocorrência de eventos de igualdade e empatia dentro do grupo. Buber (1979) e Freire (1987) chamam a atenção para a necessidade de horizontalidade. Isaacs (1999) aborda quatro habilidades a ser desenvolvidas: aprender a falar, a ouvir, a suspender (os pressupostos) e a respeitar. Faz-se necessário, assim, que essas sugestões sejam aprofundadas empiricamente no sentido de sua confirmação e ainda que outros indicadores possam ser levantados.

Considera-se aqui, portanto, que pesquisas participativas, mas especificamente aquelas com caráter de intervenção, oferecem condições privilegiadas para a averiguação da ocorrência de processos dialógicos e estabelecimento de indicadores.

Recebido em outubro de 2010 e aprovado em agosto de 2011. 


\begin{abstract}
Nota
1 Informação verbal: Andrade, um dos autores deste texto, vivenciou a experiência relatada.
\end{abstract}

\title{
Referências
}

AVANZI, Maria Rita; MALAGODI, Marco Antonio Sampaio. Comunidades Interpretativas. In: FERRARO JÚNIOR, Luiz Antonio (Org.). Encontros e Caminhos: formação de educadores ambientais e coletivos educadores. Brasília: MMA, 2005. P. 93-102.

BARBIER, René. Pesquisa-Ação na Instituição Educativa. Rio de Janeiro: Jorge Zahar, 1985.

BOGDAN, Robert; BIKLEN, Sari. Investigação Qualitativa em Educação: uma introdução à teoria e aos métodos. Coimbra/Lisboa: Porto, 1994.

BOHM, David. Diálogo: comunicação e redes de convivência. São Paulo: Palas Athena, 2005.

BRANDÃO, Carlos Rodrigues. Pesquisa Participante. In: FERRARO JÚNIOR, Luiz Antonio. (Org.). Encontros e Caminhos: formação de educadores ambientais e coletivos educadores. Brasília: MMA, 2005. P. 257-266.

BRANDÃO, Carlos Rodrigues. Repensando a Pesquisa-Participante. 8. ed. São Paulo: Brasiliense, 1999.

BRANDÃO, Carlos Rodrigues. Saber e Ensinar. 3ed. São Paulo: Papirus, 1986.

BRASIL. Programa Nacional de Formação de Educadoras(es) Ambientais: por um Brasil educado e educando ambientalmente para a sustentabilidade. Série Documentos Técnicos, n. 8. Brasília: Órgão Gestor da Política Nacional de Educação Ambiental, 2006.

BRASIL. Programa Nacional de Educação Ambiental. Ministério do Meio Ambiente. Departamento de Educação Ambiental; Ministério da Educação, Coordenação Geral da Educação Ambiental, 3. ed. Brasília: MMA, 2005.

BRASIL. Decreto n. 4.281 de 25 de junho de 2002. Regulamenta a Lei no 9.795, de 27 de abril de 1999, que institui a Política Nacional de Educação Ambiental, e dá outras providências. Diário Oficial da União, Brasília, DF, 26 jun. 2002. Disponível em: < http://www.planalto.gov.br/ccivil_03/decreto/2002/D4281.htm>. Acesso em: 22 jun. 2012.

BRASIL. Lei n. 9.795, de 27 de abril de 1999. Dispõe sobre a Educação Ambiental, institui a Política Nacional de Educação Ambiental e dá outras providências. Diário Oficial [da] República Federativa do Brasil, Brasília, DF, 28 abr. 1999. Disponível em: <http://www4.planalto.gov.br/legislacao/legislacao-1/leis-ordinarias/legislacao-1/ leis-ordinarias/1999\#content>. Acesso em: 30 jul. 2010.

BUBER, Martins. Eu e Tu. 2. ed. São Paulo: Cortez e Moraes, 1979.

COSTA-PINTO, Alessandra Buonavoglia; LUCA, Andréa Quirino de; CASTELLANO, Maria. Coletivo Educador Ambiental de Campinas (COEDUCA): uma análise preliminar de sua dinâmica interna de participação. In: Encontro Nacional da ANPPAS, 4., jun 2008, Brasília. Anais... Brasília, 2008. 
FLORIANI, Dimas. Diálogo de saberes: uma perspectiva socioambiental. In: Ferraro Júnior, Luiz Antonio (Org.). Encontros e caminhos: formação de educadores ambientais e coletivos educadores- volume dois. Brasília: MMA, 2007. P. 105-116.

FÓRUM INTERNACIONAL DE ORGANIZAÇÕES NÃO GOVERNAMENTAIS E MOVIMENTOS SOCIAIS. Tratado das ONGs. Rio de Janeiro, 1992. P. 198-201.

FREIRE, Paulo. Educação como Prática da Liberdade. 32. ed. Rio de Janeiro: Paz e Terra, 2009.

FREIRE, Paulo. Pedagogia da Autonomia: saberes necessários à prática educativa. 14. ed. São Paulo: Paz e Terra, 2000.

FREIRE, Paulo. Pedagogia do Oprimido. 26. ed. Rio de Janeiro: Paz e Terra, 1987.

ISAACS, William. Dialogue and the Art of Thinking Together: a pioneering approach to communicating in business and in life. New York: Doubleday, 1999.

ISAACS, William. Taking Flight: dialogue, collective thinking and organizational learning. Organizational Dynamics, v. 22, n. 2, Autumn 1993. P. 24-39.

ISAACS, William. The Dialogue Project Annual Report 1993-1994, s.d., Available in: $<$ http://www.solonline.org/res/wp/8004.html>. Acesso em: 30 jul. 2010.

LUCA, Andréa Quirino de; COSTA-PINTO, Alessandra Buonavoglia; CARDOSO, Mario Mariano Ruiz. Uma Análise Preliminar da Trajetória de Formação dos Educadores-Articuladores do Coletivo Educador Ambiental de Campinas. In: ENCONTRO DE PESQUISA EM EDUCAÇÃO AMBIENTAL, 5, 2009, São Carlos. Anais... São Carlos, 2009.

MALAGODI, Marco Antonio Sampaio. Conflitos: conflitos, discórdias, polêmicas, desentendimentos... Estorvando a ordem conformista e desbloqueando a aprendizagem social. In: FERRARO JÚNIOR, Luiz Antonio (Org.). Encontros e Caminhos: formação de educadores ambientais e coletivos educadores, v. 2. Brasília: MMA, 2007. P. 71-84. MINAYO, Maria Cecília de Souza. Pesquisa Social: teoria, método e criatividade. Petrópolis: Vozes, 1998.

NETO, Otavio Cruz; MOREIRA, Marcelo Rasga; SUCENA, Luiz Fernando Mazzei. Grupos Focais e Pesquisa Social Qualitativa: o debate orientado como técnica de investigação. In: ENCONTRO DA ASSOCIAÇÃO BRASILEIRA DE ESTUDOS POPULACIONAIS, 8, 2002, Ouro Preto. Anais... Ouro Preto, 2002. Disponível em: $<$ http://www.abep.nepo.unicamp.br/docs/anais/pdf/2002/Com_JUV_PO27_Neto_texto. pdf>. Acesso em: 18 ago. 2009.

OLIVEIRA, Haydée Torres. Transdisciplinaridade. In: FERRARO JÚNIOR, Luiz Antonio (Org.). Encontros e Caminhos: formação de educadoras(es) ambientais e coletivos educadores. Brasília: MMA/DEA, 2005. P. 333-342.

ROCHA, Maria Lopes da. Psicologia e as Práticas Institucionais: a pesquisa-intervenção em movimento. Psico, Porto Alegre, Pontifícia Universidade Católica do Rio Grande do Sul, v. 37, n. 2, p. 169-174, maio/ago. 2006.

ROCHA, Marisa Lopes da; AGUIAR, Katia Faria de. Pesquisa-Intervenção e a Produção de Novas Análises. Psicologia Ciência e Profissão, Brasília, v. 23, n. 4, p. 64-73, dez. 2003.

SANTOS, Boaventura de Souza. Pela Mão de Alice: o social e o político na pósmodernidade. 12. ed. São Paulo: Cortez, 2008. 
SANTOS, Boaventura de Souza. A Crítica da Razão Indolente: contra o desperdício da experiência. 6. ed. São Paulo: Cortez, 2007.

SCHEIN, Edgar. On Dialogue, Culture and Organizational Learning. In: ISAACS, William. Organizational Dynamics, v. 22, n. 2, autumn 1993.

TASSARA, Eda Terezinha de Oliveira; ARDANS, Omar. Intervenção Psicossocial: desvendando o sujeito histórico e desvelando os fundamentos da educação ambiental critica. In: FERRARO JÚNIOR, Luiz Antonio (Org.). Encontros e Caminhos: formação de educadoras(es) ambientais e coletivos educadores. Brasília: MMA/DEA, 2005. P. 201-216.

THIOLlENT, Michel. Metodologia da Pesquisa-Ação. São Paulo: Cortez, 1985.

TOZONI-REIS, Marília Freitas de Campos. Pesquisa-Ação. In: FERRARO JÚNIOR, Luiz Antonio (Org.). Encontros e Caminhos: formação de educadores ambientais e coletivos educadores. Brasília: MMA, 2005. P. 267-276.

VALLES, Miguel. Técnicas Cualitativas de Investigación Social: reflexión metodológica y práctica profesional. Madrid: Síntesis, 1997.

VIEZZER, Moema. Pesquisa-ação-participante (PAP): origens e avanços. In: FERRARO JÚNIOR, Luiz Antonio (Org.). Encontros e Caminhos: formação de educadores ambientais e coletivos educadores. Brasília: MMA, 2005. P. 277-294.

YANCHELOVICH, Daniel. The Magic of Dialogue: transforming conflict into cooperation. New York: Touchstone, 2001.

Andréa Quirino de Luca é bióloga, doutoranda em Ciência Ambiental pelo Programa de Ciência Ambiental (PROCAM) da USP/SP. Pesquisadora da OCA - Laboratório de Educação e Política Ambiental do Departamento de Ciências Florestais da ESALQ/USP Piracicaba, São Paulo.

E-mail: andreaqluca@gmail.com

Daniel Fonseca de Andrade é biólogo, doutorando em Ciência Ambiental pelo Programa de Ciência Ambiental (PROCAM) da USP/SP. Pesquisador da OCA - Laboratório de Educação e Política Ambiental do Departamento de Ciências Florestais da ESALQ/USP Piracicaba, São Paulo.

E-mail: dfa@netsite.com.br

Marcos Sorrentino é professor no Departamento de Ciências Florestais da ESALQ/USP Piracicaba; Coordenador da OCA - Laboratório de Educação e Política Ambiental do Departamento de Ciências Florestais da ESALQ/USP Piracicaba, São Paulo.

E-mail: sorrentino.ea@gmail.com 